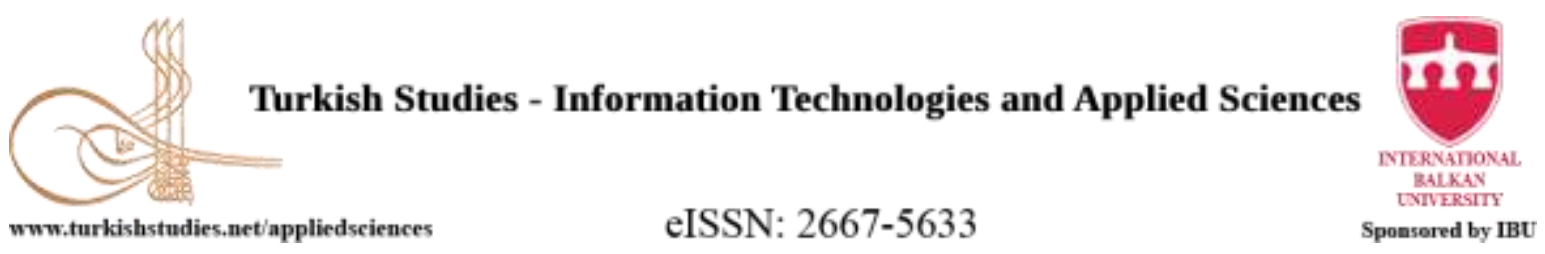

Research Article / Araştırma Makalesi

\title{
Binalarda Enerji Verimliliği Sağlanması İçin Kablosuz Algılayıcı Ağı, Çok Boyutlu Veri Ambarı, Karar Destek Yazılımı ve Ağlı Gömülü Donanımlardan Oluşan Sistemin Araştırılması, Geliştirilmesi ve Doğrulanması
}

\author{
Research, Development and Validation of a System Consisting of a Wireless Sensor Network, \\ Multi-Dimensional Data Warehouse, Decision Support Software and Wireless Network Embedded \\ Hardware for Improving Energy Efficiency in Buildings
}

\author{
Kamil Umut Gökçe ${ }^{*}$ - Hasan Ufuk Gökçe**
}

\begin{abstract}
In this work, a cost effective building energy optimization system consisting of 12 different wireless network embedded sensors, control units (actuators), wireless communication protocol, multidimensional data warehouse, graphical user interfaces and energy optimization software with artificial intelligence based control algorithms is examined. The research and development activity is carried within the "Indigenous Sensor Development for Energy Efficient Buildings" research project which is supported by "The Scientific and Research Council of Turkey" (TÜBITTAK) - Teydeb 1501 Industry Research and Development Projects programme between 2014 and 2018. The "EOS Energy Optimization System", which is subject to this research, reduces the total energy use of buildings through optimisation of energyconsuming building systems such as heating, cooling, lighting systems and home/office appliances with the support of an integrated system consisting of artificial intelligence based software and wireless hardware. The developed system has been tested, and energy efficiency levels were measured at the Boğaziçi University North Campus Technology Center (TEKMER), EOS Sustainable Energy Solutions A.Ş. firm's office and laboratory areas between the years 2014-2018. It has been recorded that the system provides energy efficiency levels between the lowest $30,23 \%$ - the highest $41,27 \%$ under different seasonal and occupancy conditions. The developed system can be deployed to all types of historical and new buildings to reduce energy consumption.
\end{abstract}

Structured Abstract: Turkey imports 76\% of its total energy (Gökçe \& Erol 2020: 108) and 96\% of its oil (EUROSTAT b, 2020). Turkey paid 350 Billion U.S. Dollars for energy imports between the years 2011 and 2017 (BOTAS, 2017: 17). It is estimated that Turkey will import approx. 1.1 to 1.4 Trillion U.S. Dollars worth of energy until the year 2030 (OME, 2014: 18). Current residential and office buildings significantly contribute to total energy consumption and $\mathrm{CO}_{2}$ emissions. Energy consumption for building-related services accounts for approximately $40 \%$ of total EU energy consumption (Itard vd., 2008:19). Buildings are

\footnotetext{
* Dr. Öğr. Üyesi, Genel Müdür, EOS İstanbul Sürdürülebilir Enerji Çöz. A.Ş., İTÜ ARI Teknokent, İstanbul. Asst. Prof. Dr.-Ing., Managing Director, EOS Istanbul Sustainable Energy Sol. Inc., ITU ARI Teknokent, Istanbul. ORCID 0000-0000-0000-0000

umut.gokce@eos-ses.de

** Dr. Öğr. Üyesi, Ar\&Ge Müdürü, EOS İstanbul Sürdürülebilir Enerji Çöz. A.Ş. İTÜ ARI Teknokent, İstanbul. Asst. Prof. Dr., R\&D Director, EOS Istanbul Sustainable Energy Sol. Inc. ITU ARI Teknokent, Istanbul. ORCID 0000-0001-8010-0703

ufuk.gokce@eos-ses.de
}

Cite as/ Atıf: Gökçe, K., U. \& Gökçe, H. U. (2020). Binalarda enerji verimliliği sağlanması için kablosuz algılayıcı ağı, çok boyutlu veri ambarı, karar destek yazılımı ve ağlı gömülü donanımlardan oluşan sistemin araştırılması, geliştirilmesi ve doğrulanması. Turkish Studies - Applied Sciences, 15(3), 345-360. https://dx.doi.org/10.47844/TurkishStudies.43963

Received/Geliş: 03 June/Haziran 2020

Accepted/Kabul: 20 September/Eylül 2020

Copyright $($ INTAC LTD, Turkey

Checked by plagiarism software

Published/Yayın: 25 September/Eylül2020

CC BY-NC 4.0 
responsible for $36 \%$ of the total $\mathrm{CO}_{2}$ emissions (EC, 2014:18). It has been estimated that building operation (space lighting, heating and cooling) is responsible for about $50 \%$ of primary energy use and a slightly lower share of $\mathrm{CO}_{2}$ and greenhouse gas emissions in the $\mathrm{EU}$ (Cohen et al. 2004). Reports by the Intergovernmental Panel on Climate Change (IPCC) and the U.S. Department of Energy note that buildings account for 25-30\% of the total energy-related $\mathrm{CO}_{2}$ emissions worldwide (Price, 2006). It is clear that with efficiency initiatives in the building sector, significant energy savings and $\mathrm{CO}_{2}$ emission reductions can be achieved, thus helping to attain objectives on climate change and security of energy supply.

On the basis of on-going research in the area of energy efficiency and legislative drivers launched by the national and international organizations, the role of integration concepts, energy performance monitoring, analysis methodologies and sophisticated intelligent control strategies through the seamless integration of people, ICT devices and computational resources gain significant importance for reducing the energy consumption and the operational costs. The International Energy Agency (IEA) set Eco-Design Strategies in order to increase the energy efficiency of buildings. Among these strategies home automation systems are the most cost-effective solution without requiring heavy refurbishments (Gökçe, 2010).

According to European standard "EN 15232 Energy Performance of Buildings-Impact of Building Automation" building operation systems can, depending on building type and equipment standard, produce the following potential savings of energy: restaurants $31 \%$, hotels $25 \%$, offices $39 \%$, shopping centers $49 \%$, hospitals $18 \%$, schools/universities $34 \%$ and residential 27\% (DIN, 2007). This is a major contribution to the "Kyoto-Protocol-Process" in which the EU outlined the objective to reduce energy consumption by $20 \%$ by 2020 (EC, 2011:3). Moreover, the control of energy performance of buildings is often provided by an ad-hoc combination of off-the-shelf building management components, distributed data metering equipment, glued together by monitoring and targeting software tools. The absence of building management systems standardization coupled with competition for market share results in independent and non-compatible system development.

In this context, the objective of this work is to research a methodology for developing a system which processes and analyses building performance data. Ultimately, to monitor and intelligent control of building operations for reducing energy consumption. In order to reach this objective, new methods and tools are researched which increase system functionality covering the recent building energy regulations, wireless embedded technologies, intelligent control algorithms, monitoring tools and integration of these to the information management backend system-the Data Warehouse (DW) core through a indigenously developed wireless sensor network.

In this work, a building energy optimization system consisting of 12 different wireless network embedded sensors, control units, wireless communication protocol, multi-dimensional data warehouse, graphical user interfaces and energy optimization software consisting of artificial intelligence based control algorithms is examined. The research is carried within the "Indigenous Sensor Development for Energy Efficient Buildings" research project which is supported by The Scientific and Research Council of Turkey" (TÜBİTAK) - Teydeb 1501 Industry R\&D Projects programme between 2014 and 2018.

The "EOS Energy Optimization System", which is subject to this work, is developed as a new integrated data collection and building energy optimisation system, providing open, expandable information exchange for energy performance monitoring and optimisation using wireless network embedded hardware, multi-dimensional data warehouse core with data mining technologies and artificial intelligence backed decision support software.

The developed system consists of the following key elements: (1) Indigenously developed wireless hardware. (2) Wireless communication protocol. (3) A unique, multi-dimensional information management platform offering e-services for energy performance monitoring and intelligent control using data warehouse technologies, data mining, and web-services. (4) A new, open, extensible data exchange method named the Extraction, Transformation and Loading (ETL) Tool facilitates the interoperability of the tools. (5) An Intelligent Control module optimizes the energy consumption of the building systems for the different use cases and scenarios. (6) Context sensitive, web-based, Graphical User Interfaces for multiple stakeholders.

In this work, seven development phases are considered. In the first phase of the study, the analyses of the sensors, control units (actuators) that can be used for energy efficiency, and the network structures that can be used in this context have been analysed and the requirement analysis on the existing systems have 
been completed. In the following phase, a specification study was conducted for all components and equipment determined on the basis of requirement analysis, and all associated features were listed. In the third and fourth phases of the project, original design and hardware activities and embedded software development activities were completed on the basis of specifications. In the fifth and sixth phases, the original PCB designs have been completed. In the seventh phase, the final software and hardware were developed for the end user. In addition, at this stage, artificial intelligence-based intelligent control algorithms have been completed to provide optimization between the sensors.

The developed system was tested, and energy efficiency levels were measured at the Boğaziçi University North Campus Technology Center (TEKMER), EOS Sustainable Energy Solutions A.Ş. firm's office and laboratory areas in the period of 2014-2018. It has been recorded that the system can provide energy efficiency between $30,23 \%$ and $41,27 \%$ under different seasonal and occupancy conditions.

Keywords: Management Information Systems, Civil Engineering, Smart Buildings, Energy Efficiency, Decision Support Systems, Information Management, System Development, Machine Learning, Network Embedded Technologies, Optimization and Techniques.

Öz: Bu çalışmada, TÜBİTAK Teydeb 1501 Sanayi AR-GE Projeleri Destekleme Programı çerçevesinde 2014-2018 yılları arasında yürütülmüş 3140107 proje numaralı "Binalarda Enerji Verimliliği için Gerekli Algılayıcıların Özgün Olarak Geliştirilmesi Projesi" kapsamında binaların enerji verimliliğinin arttırılması hedefi için gerekli olan ağlı gömülü teknolojileri içeren 12 farklı tipte özgün olarak geliştirilmiş sensör ve kontrol ünitesi, bunlara ait gömülü yazılımlar, kablosuz haberleşme protokolü, çok boyutlu veri ambarı, yapay zeka tabanlı akıllı kontrol algoritmalarından oluşan enerji optimizasyon yazılımı ve grafiksel kullanıcı ara yüzlerinden meydana gelen entegre Enerji Optimizasyon Sistemi (EOS) ele alınmıştır. Bu çalışmaya konu olan "EOS Enerji Optimizasyon Sistemi" açık ve genişletilebilir bilgi alışverişi ile birlikte yenilikçi bir entegre veri toplama ve bina yönetim sistemi olarak ortaya konmuş, veri ambarı, veri madenciliği, akıllı kontrol ve web hizmeti teknolojilerini kullanarak enerji performans izleme ve optimizasyonunun gerçekleştirilmesini sağlamıştır. Geliştirilen sistem Boğaziçi Üniversitesi Kuzey Yerleşkesi Teknoloji Merkezi (TEKMER) içinde yer alan EOS Sürdürülebilir Enerji Çözümleri A.Ş. firmasına ait ofis ve laboratuvar alanlarında konuşlandırılarak test edilmiş ve enerji verimlilik seviyeleri ölçülmüştür. Geliştirilen sistem kablosuz donanımlar ve yapay zekâ algoritmalarından oluşan yazılım yardımı ile 1sıtma/soğutma sistemleri, ışıklandırma, ev gereçleri gibi enerji harcayan bina sistemlerini optimize ederek binaların toplam enerji kullanımını maliyet etkin bir şekilde düşürmektedir. EOS eski, yeni ve farklı kulanım amaçlarına sahip binalarda uygulanabilmektedir. Yapılan testler sonucunda geliştirilen sistemin farklı mevsimsel koşullar altında en düşük \%30,23 ile en yüksek \%41,27 aralığında enerji verimliliği sağladığı kayıt altına alınmıştır.

Anahtar Kelimeler: Yönetim Bilişim Sistemleri, İnşaat Mühendisliği, Akıllı Binalar, Enerji Verimliliği, Karar Destek Sistemleri, Bilgi Yönetimi, Sistem Geliştirme, Makine Öğrenmesi, Ağlı Gömülü Teknolojiler, Optimizasyon ve Teknikleri.

\section{Giriş}

Türkiye enerji ihtiyacının yüzde 76'sını ithal ederek karşılamaktadır (Gökçe \& Erol 2020: 108). Enerjide ithalata bağımlılıkta 39 Avrupa ülkesi içinde 5. sırada yer almaktadır (EUROSTAT a, 2020). Enerjide ithalata bağımlıkta $28 \mathrm{AB}$ ülkesinin ortalaması ise $\% 55$ oranındadır (EUROSTAT a, 2020). Türkiye'nin sadece petrolde ise \%96 oranında ithalata bağımlılı̆̆ bulunmaktadır (EUROSTAT b, 2020). T. C. Enerji ve Tabii Kaynaklar Bakanlığı verilerine göre Türkiye, 2011 ve 2017 yılları arasında yaklaşık 350 milyar Amerikan Dolar'1 tutarında enerji ithalatı yapmıştır (BOTAS, 2017: 17). 2017 yılında 37 milyar 204 milyon 849 bin doları bulan enerji ithalat1, 2018 y1lında yaklaşık yüzde 15,6 artarak 42 milyar 999 milyon 451 bin dolara yükselmiştir. Ulusal Enerji Denge Tablosuna göre 2017 y1lında 145,3 mtpe olan Ülkemizin birincil enerji talebinin 2023 y1l itibarıla 218 mtpe'ye ulaşması beklenmektedir (BOTAS, 2019: 15). Akdeniz Ülkeleri Enerji Şirketleri Birliği tarafından hazırlanan 4'üncü Akdeniz Enerji Perspektifleri - Türkiye başlıklı raporda, Türkiye'nin enerji ithalatı faturasının 1970-2012 yıllarına 
göre 2013-2030 yılları arasında iki katına çıkacağı ortaya konmuştur. Türkiye'nin 2030 yılına kadar 1,1 - 1,4 trilyon Amerikan Dolar'1 tutarında enerji kaynağı ithal etmesi öngörülmektedir (OME, 2014: 18).

Günümüzde Avrupa Birliği ülkelerinde kullanılan toplam enerjinin \%40'1 sadece binalar (konut ve ofis) tarafindan tüketilmektedir (Itard vd., 2008: 19). Avrupa genelinde binalar toplam karbon emisyonlarının \%36'sını üretmektedir (EC, 2011: 48). Yapılan orta ve uzun vadeli projeksiyonlarda öngörüldügü üzere, 2030 yılı itibari ile binalar başlıca enerji kullanıcısı olarak dünyadaki toplam enerjinin \%35'ini kullanacak ve zararlı sera gazı emisyonları salınımında kritik rol oynamaya devam edeceklerdir (Price, 2006: 14). Avrupada binaların \%85'i 20 yıldan ve \%60'1 40 yıldan eski olmakla beraber, \%30'u ikinci dünya savaşı öncesi inşa edilmiş binalardır, bu görece eski ve enerji verimliliği düşük bina stoğunun \%50'ye tekabül eden bölümü önümüzdeki 10 sene içerisinde mevcut Avrupa Birliği Enerji Verimliliği Müktesabatına uygun hale getirilmek üzere yenilenecektir (Bogdan vd., 2011: 9). Mevcut binaların enerji verimliğinin arttırılmasına yönelik çözümler yüksek bir ticari potansiyel taşımaktadırlar.

Binalar tarafından kullanılan enerji miktarının \%30 oranında optimize edilmesi ile Avrupa'da kullanılacak toplam enerji miktar1 \%11 oranında azalacaktır (Bogdan vd., 2011: 43). Bu yaklaşım, enerji kullanımında geri kalan \%60'lı dilimin içinde yer alan endüstri ve ulaşım kaynaklı enerji kullanımında hiçbir iyileştirme yapılmasa dahi, Avrupa Birliği hedefi olan 2020 y1lında kullanılacak toplam enerji miktarı verimliliğinin \%20 oranında arttırılmasını (EC, 2011: 3) mümkün kılacak ve hedeflenen verimlilik değerlerinin yarıdan fazlasını sadece binalarda iyileştirme yapılması ile karşılayacaktır.

Enerjinin her alanda verimli bir şekilde kullanılması ve doğal kaynaklardan elde edilen yenilenebilir enerji, sektörlerin geleceğidir. Almanya'nın Bonn şehrinde yapılan Birleşmiş Milletler Klima Konferansında (COP 23 UN-Klimakonferenz in Bonn, 2017) bütün katılımcı ülkelerin kabul ettiği üzere çevreci teknolojiler ve çevreyi koruma ile ilgili yaptırımlar ve teşvikler önemli oranda arttırılacaktır (UNFCCC, 2018: 13). Bu da, yenilenebilir kaynaklardan üretilen elektrik enerjisine ve enerjinin verimli kullanılmasını sağlayan maliyet etkin akıllı enerji optimizasyon teknolojilerine olan talebi küresel ölçekte arttıracaktır.

Uluslararası Enerji Ajansı (IEA) raporları ve farklı akademik çalışmalar, gelişmiş bina kontrol sistemlerinin binaların enerji tüketiminin azaltılmasına \% 40 oranında katkıda bulunabilir olduğunu göstermektedir (DIN, 2007: 1 VDMA, 2008:69, Becker \& Knoll, 2011: 7).

$\mathrm{Bu}$ yaklaşım, Kyoto Protokolü Süreci ve Avrupa Birliğinin 2020 yılı sonuna kadar enerji tüketiminin \%20 oranında azaltılması için koymuş olduğu hedefle de örtüşmektedir. Avrupa'da son 30 yılda yapılmış olan çoğu bina (konutlar hariç) kablolu bina otomasyon sistemleri ile donatılmıştır.

Ancak, genellikle bu sistemler farklı ve birbirleri ile bütünsellik arz etmeyen ürünlerin kullanılması ile oluşturulmuştur. Bu gelişi güzel kurulmuş olan sistemler, bina sahiplerine bu sistemlerin geliştirilmesi ve yönetimi ile ilgili büyük sorunlar yaşatmaktadır. Enerji üretimi, yönetimi ve verimliliği için gerekli olan sistem optimizasyonu, bu sistemlerin tasarım ve yönetim prosedürlerine karmaşı olan bir katman daha eklemektedir. Bu problemin çözümü, sistem analizlerinin yapılması, yeni sistemlerin kurulması ve yeni arayüz yazılımlarının yazılması ile gerçekleştirilebilir. Binalarda gerekli cihazların kurulması, mevcut sistemlerden veri toplama, karmaşık radyo yayılım özelliklerinin ele alınması, deneme-yanılma ile yoğun el işi gerektiren süreçleri kapsamaktadır (Keller vd., 2008: 1). Bu aktiviteler için gerekli olan bilişim teknolojileri desteği ve bu konuda eğitimli bina yöneticileri yeterli değildir (Jagemar vd., 2007: 1).

Son dönemde yaşanan gelişmeler çerçevesinde ağlı gömülü teknolojiler birçok alanda ön plana çıkmaktadır. Bu sistemler, ortam izleme ve kontrol uygulamaları için kullanılırlar. Bu 
özellikleri maliyetlerinin de ucuz olması nedeni ile binalarda enerji performansının ayrıntılı olarak ölçülmesi için kullanılabilir olabileceklerini teyit etmektedir.

Özellikle çok boyutlu performans verisi analizleri için kullanılacak verinin toparlanabilmesi için gerekli sistem altyapısının kablosuz algılayıcı ve algılayıcı ağ yapıları üzerine kurulması yeni bir çalışma alanı olup, binalarda enerji verimliliği için gerekli olan sistem mimarisinin etken elemanlarından biri halini almaktadır.

\section{Proje Amaci}

TÜBİTAK Teydeb 1501 Sanayi AR-GE Projeleri Destekleme Programı çerçevesinde yürütülmüş 3140107 proje numaralı "Binalarda Enerji Verimliliği için Gerekli Algılayıcıların Özgün Olarak Geliştirilmesi Projesi" kapsamında, enerji tüketimini azaltmaya yönelik bina operasyonlarının izlenmesi ve akıllı kontrolü için gerekli olan bina performans verilerini işleyen ve analiz eden bütünleşik bir sistemin ortaya konması için yeni bir metodoloji geliştirilmiştir.

Bu amaca ulaşmak için, yürürlükte olan bina enerji düzenlemeleri, kablosuz gömülü cihazlar, akı1lı kontrol algoritmaları, bina enerji performansı izleme araçları, bu araçların bilgi yönetimi, bu araçlardan elde edilen bilgilerin veri ambarı entegrasyonunu kapsayan ve sistem işlevselliğini artıran yeni yöntemler araştırılmıştır.

Bu çalışmaya konu olan "EOS Enerji Optimizasyon Sistemi”" açık ve genişletilebilir bilgi alı̧̧verişi ile birlikte yeni bir entegre veri toplama ve bina yönetim sistemi olarak ortaya konmuş, veri ambarı, veri madenciliği, akıllı kontrol ve web hizmeti teknolojilerini kullanarak enerji izleme ve kontrolünün gerçekleştirilmesini sağlamıştır. Geliştirilen sistem kablosuz donanımlar ve yapay zekâ algoritmalarından oluşan yazılım yardımı ile 1sıtma/soğutma sistemleri, ış1klandırma, ev gereçleri gibi enerji harcayan bina sistemlerini optimize ederek binaların toplam enerji sarfiyatını $\% 31$ ile \%41 arasında oranlarda düşürmektedir. EOS eski, yeni ve farklı kulanım amaçlarına sahip binalarda uygulanabilmektedir.

$\mathrm{Bu}$ sistem, aşağıda verilen yaklaşımlar ve geliştirme süreçleri temelinde oluşturulmuştur:

1. Kullanıcı ve sistem gereksinimlerine göre entegre yapıda çalışabilen enerji verimliliği sağlayan çözüm uygulamalarının gelişimine olanak tanıyan yeni bir sistem geliştirme platformunun oluşturulmas1,

2. Mevcut bileşenlerin optimizasyonunu hedefleyen yeni bir modüler modelleme yaklaşımının teşkil edilmesi,

3. Veri ambarı teknolojilerini, veri madenciliğini ve web hizmetlerini kullanarak izleme ve akıllı kontrol için gerekli çok boyutlu işlem platformunun oluşturulması,

4. Farklı araçların birlikte çalışabilirliğini kolaylaştıran Çıkarma, Dönüştürme ve Yükleme (ÇDY) Aracı adlı yeni, açık, genişletilebilir bir veri alışverişi yönteminin geliştirilerek teşkil edilmesi,

5. Farklı kullanım durumları ve senaryoları için bina sistemlerinin enerji tüketimini optimize eden Akıllı Kontrol modülünün teşkil edilmesi ve,

6. Birden fazla paydaş için bağlama duyarlı, web tabanlı, Grafik Kullanıcı Arayüzlerinin oluşturulması.

$\mathrm{Bu}$ süreçler temelinde geliştirilen sistemin prototipleri proje kapsamında, Boğaziçi Üniversitesi kuzey yerleşkesi TEKMER binasında yer alan EOS İstanbul Sürdürülebilir Enerji Çözümleri A.Ş. firmasına ait ofis, laboratuvar ve İstanbul ili Bahçeşehir semtinde yer alan konut olarak kullanılan iki farklı test binasında, 2014-2018 yılları arasında test edilmiştir. 


\section{Sistem Mimarisi}

Geliştirilen sistem mimarisi, entegrasyon kavramlarını, bütünsel izleme ve analiz metodolojilerini, yaşam döngüsüne yönelik karar destek süreçlerini bilgi ve iletişim teknolojilerini destekler ve Şekil 1'de gösterildiği gibi, performans verileri (örn. enerji tüketimi, sıcaklık, aydınlatma seviyesi), sistem verileri (örn. elektrik anahtar ayarları) ve süreç bilgileri (örn. muayene, bakım, onarım) gibi bina bilgilerinin birden çok boyutunu entegre eden modüler bir platformun uygulanmasını kapsar.

Geliştirilen sistem mimarisi şu üç uygulama katmanından oluşur:

1. Kablosuz Algılayıcı Ağı Katmanı,

2. Bilgi İşlem Katmanı,

3. İzleme ve Optimizasyon Katmanı.

Şekil 1: EOS-Enerji Optimizasyon Sistemi Mimarisi.

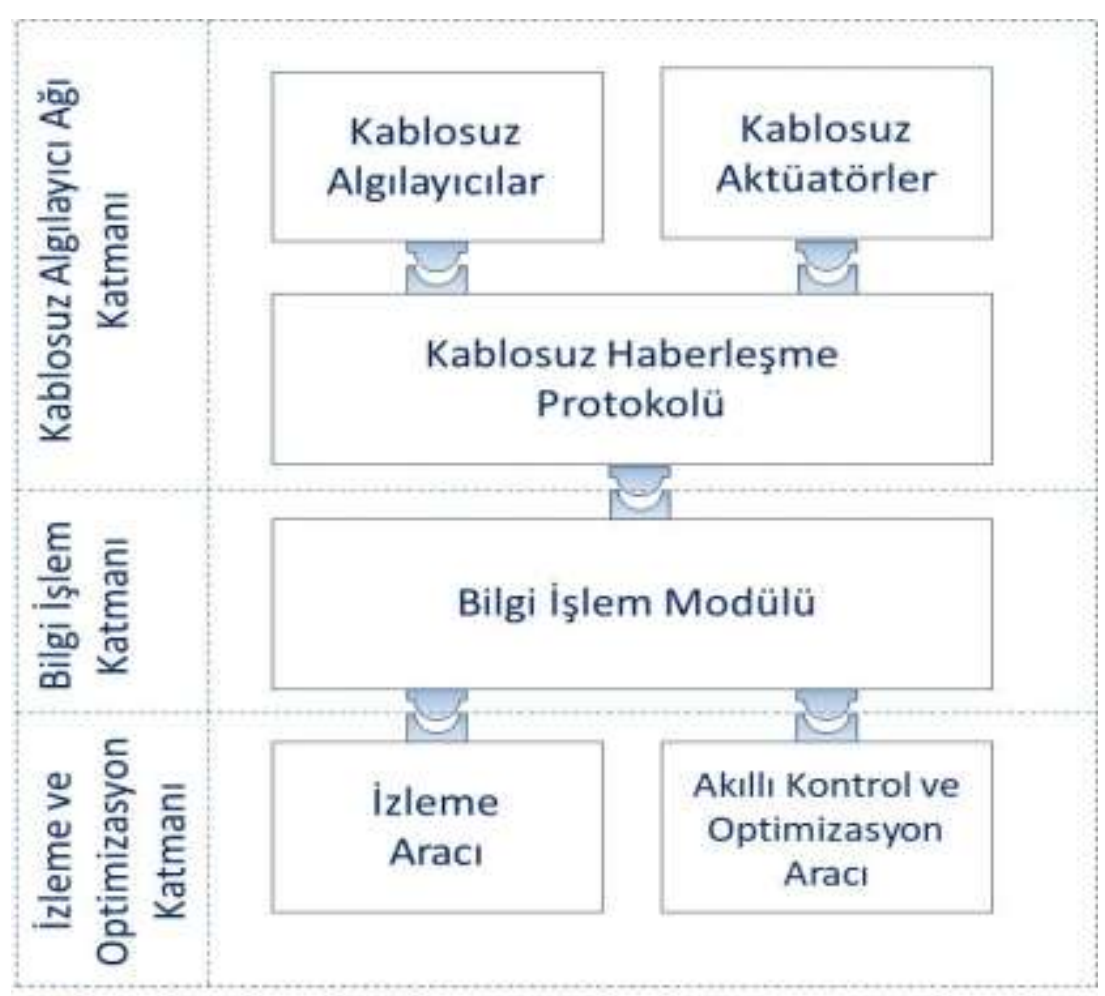

\section{Ag̈ Servisleri}

\section{Kablosuz Algılayıcı A $\breve{g} ı$ (KAA) Katmanı}

Kablosuz Algılayıcı Ağı (KAA) katmanı, kablosuz algılayıcılar ve kontrol ünitelerinden (aktüatör) oluşan sistem bileşenlerinden müteşekkil olup uygulama alanındaki belirli bölgelere ait ilgili ölçümleri ve sistem durumunu bir sonraki katmana iletir. Bu bileşenlerden toplanan veriler ham ve işlenilemez bilgiler olduğu için, bilgi işlem biriminde tanım verileri ile eşleştirilerek siniflandırılmasi yapilır.

Mote olarak da adlandırılan algılayıcılar, belirli konumlara ait sıcaklık, nem, $\mathrm{CO}_{2}, 1$ şı seviyesi vb. gibi bilgileri toplamak üzere ölçüm yapılacak yapıda yer alan belirli bölgelere yerleştirilir. Bu küçük algılayıcılar birbirleri ile kablosuz iletişim protokolleri vasıtası ile iletişim kurar. Algılayıcıların gerçek işlevselliği kablosuz sensör ağlarıyla doğru orantılıdır. 
Kablosuz algılayıcı ağları, onlarca kablosuz algılayıcı aracıllğıyla toplanan bilgileri internete veya bir yerel alan ağına aktarabilir. Son olarak, bilgi kablosuz kontrol ünitelerini kontrol etmek için analiz edildiği Bilgi İşlem Katmanında toplanmaktadır.

\section{Bilgi İşlem Katmanı (BİK)}

Bilgi İşlem Katmanı, geliştirilen sistem mimarisinin veri ve bilgi işlem operasyonları için geliştrilmiş veri tabanı ve çok boyutlu veri ambarından oluşmaktadır. KAA katmanında toplanan veriler, izleme ve optimizasyon katmanı için harekete geçirilebilir bilgileri sağlamak üzere bu katman içinde toplanır, işlenir, analiz edilir ve uzun süreli analizlerde de kullanılmak için saklanır.

Bilgi İşlem Katmanı iki bileşenden oluşur. Bunlar: (1) Çıkarma, Dönüştürme ve Yükleme (ÇDY) Arac1 ve (2) Bilgi İşlem Modülüdür.

\section{ÇYD Aracı}

Verilerin düzenli olarak Bilgi İşlem Modülüne yüklenmesi gerekir. Bunu yapmak için, bir veya daha fazla işletim sisteminden gelen verilerin elde edilmesi ve veri ambarına yüklenmesi gerekir. Kaynak sistemlerden veri elde edilmesi ve veri ambarına getirme işlemine genellikle Çıkarma, Dönüştürme ve Yükleme anlamına gelen ÇYD denir (Kimball, 2004: 29).

Önerilen sistem için ÇYD aracı, ölçüm akışı gibi uzun vadeli dinamik verileri depolayan olgu verileri tablosunu doldurmak için kullanılır. Ayrıca ÇYD aracı, mimari veriler ve 1sıtma, havalandırma ve klima sistemleri için gerekli verileri oluşturma gibi nispeten statik verileri depolayan boyutsal tabloları doldurmak için de kullanılabilir (Gökçe \& Gökçe, 2013: 14).

\section{Bilgi İşlem Birimi}

Çeşitli kaynaklardan toplanan bilgilerin, geliştirilen aracın (örn. Akıllı kontrol ve optimizasyon aracı) ve paydaşların gereksinimleri için işlenmesi ve toplanması gerekir. Bu çok boyutlu bir bilgi yönetim platformu gerektirir (Gökçe \& Gökçe, 2011: 3).

Veri ambarı sistemleri, içinde depolanan bilgileri entegre etmek ve sorgulamak için bir dizi alternatif yol sağlar. Böylece, "Çevrimiçi Analitik İşleme (OLAP)" ile birleştirilmiş veri ambarı, son kullanıcıların farklı koşullar altında bina performansını analiz etmelerini ve anlamalarını sağlar (Gökçe \& Gökçe, 2013: 4).

Veri ambarı, operasyonel veriler yerine özetlenmiş bilgileri depolar. Bu özetlenmiş bilgiler zamanla değişkendir ve "Dış sıcaklık $21^{\circ} \mathrm{C}$ olduğunda belirli bir binadaki belirli bir odanın enerji tüketimi" gibi sorulara etkili cevaplar sağlar.

\section{İzleme ve Optimizasyon Katmanı}

Bilgi işleme katmanı tarafından sağlanan harekete geçilebilir bilgiler, kontrol ve optimizasyon katmanında, enerji performans izleme, akıllı kontrol ve enerji optimizasyonu işlemlerini gerçekleştirmek için kullanılır.

\section{İzleme Aracı}

İzleme aracının amacı, bina enerji performans bilgilerini web tabanlı kullanıcı ara yüzleri aracılığıyla paydaşlara sunmaktır. Bunu gerçekleştirmek için son kullanıcıların kolay sorgulama yapmasını sağlayan nesne tabanlı yazılım dili kullanılarak bir arayüz geliştirilmiştir. Ayrıca bu kullanıcı ara yüzleri son kullanıcı tercihine bağlı olarak sorgu sonuçlarını hem grafik biçiminde hem de tablo biçiminde gösterebilir. Sistem için dikkate alınan performans izleme ve yerinde teşhis gibi iki ana kullanım senaryosu vardır. 
$\mathrm{Bu}$ nedenle, iki farklı tipte kullanıcı arabirimi uygulaması geliştirilmiştir.

Bunlar (1) Performans değerlendirmesi için masaüstü uygulaması ve (2) tesis yönetimi için mobil uygulamadır. Şekil 2, sistemin grefiksel kullanıcı arayüzünü göstermektedir.

Şekil 2. EOS Kullanıc1 Arayüzü.

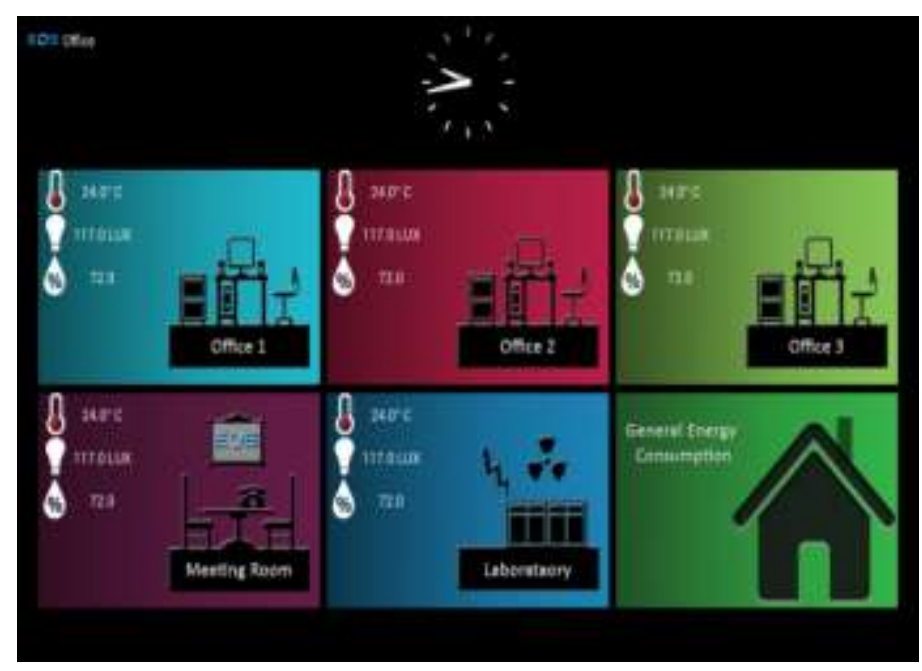

\section{Akıllı Kontrol ve Optimizasyon Aracı}

Senaryo tabanlı algoritmalar içeren Akıllı Kontrol ve Optimizasyon aracı, tanımlanmış 1sıtma, soğutma ve aydınlatma sistemleri optimizasyon senaryoları ve kontrol parametrelerini hesaplamak için bilgi işlem modülü ile etkileşime girer.

Bilgi işlem modülünün oluşturduğu harekete geçirilebilir bilgi içeren veri küpleri, akıllı kontrol ve optimizasyon aracı yazilımı tarafindan analiz edilir. Analiz algoritmalar tarafindan kullanılır ve verilen karar komutu kontrol ünitelerini (aktüator) belirlenen enerji verimliğine yönelik optimizasyon senaryoları tabanında harekete geçirmek için Kablosuz Algılayıcı Ağına (KAA) aktarılır.

KAA tarfindan gönderilen komutlar ile kablosuz aktüatörler ilgili bina enerji sistemini kontrol ederek (örn: aç, kapa, yükselt, azalt, kıs, sabitle) enerji verimliliği sağlar.

\section{Sistem Geliştirme Süreçleri}

$\mathrm{Bu}$ projemizde, sistem mimarisi temelinde, EOS Enerji Optimizasyon Sisteminin geliştirilmesine yönelik yedi aşamadan oluşan bir süreç izlenmiştir.

Çalışmanın birinci aşamasında enerji verimliliği için kullanılabilecek algılayıcıların, kontrol ünitelerinin (aktüatör) ve bu kapsamda kullanılabilecek ağ yapılarının birlikte çalışmasına yönelik analizler yapılarak mevcut sistemler üzerindeki gereklilik analizleri tamamlanmıştır. Bunu izleyen süreçte gereklilik analizleri temelinde belirlenen tüm komponent ve donanımlara yönelik olarak bir spesifikasyon çalışması yapılarak, geliştirilmesi planlanan algılayıcıların tüm özellikleri listelenmiştir. Projenin üçüncü ve dördüncü periyodunda, bu spesifikasyonlar temelinde özgün tasarım ve donanım faaliyetleri ve gömülü yazılım geliştirme faaliyetleri tamamlanmıştır. Projenin beşinci ve altıncı safhasında, yeni donanım elektronik kart tasarımları ele alınarak yapılan kart tasarımları temelinde kartlarda kullanılacak komponentlerin kart üzerine dizilmesi işlemleri ile özgün kart tasarımları tamamlanmıştır. Projenin yedinci safhasında geliştirilen yazılımın ve donanımın son kullanıcıya yönelik olarak son tasarımları yapılmıştır. Ayrıca bu safhada geliştirilen 
algılayıcılar arasındaki optimizasyonun sağlanabilmesi için yapay zeka tabanlı akıllı kontrol algoritmaları çalışmaları da bitirilmiştir.

Projenin son sahasında geliştirilen sistemin 2 farklı test binasında (konut ve ticari bina) uygulaması yapılmış ve kontrollü olarak test edilerek enerji verimlilik oranları doğrulanmıştır.

Donanım geliştirilmesi sürecinde ST Microelectronics firması üretimi ARM tabanlı 32 bit mikro işlemcileri analiz edilmiş ve geliştirilen algılayıcı ve kontrol ünitelerinde kullanılmıştır. Bu noktada STM 32 bit işlemcilerin gömülü yazılımları geleneksel $\mathrm{C} / \mathrm{C}++$ dillerine ek olarak, Microsoft.NET Micro Framework yazılım geliştirme ortamı vasıtasıyla Java ve C\# dilleri ile de programlanabilmektedir. STM 32 bit işlemci ailesinin kullanıldığı algılayıc1/kontrol üniteleri için gömülü yazılım geliştirilirken bu işlemcilere özel farklı kütüphanelerin kullanılması gerekmektedir. $\mathrm{Bu}$ proje kapsamında Java ve C\# dilleri ele alınmış ve tüm gömülü yazılımlar bu programlama dilleri ile yapılmıştır. Donanımlar için kullanılan panolarda ARM tabanlı mikro işlemciler (STM 32 F3, STM 32 F1, STM 32 F0, STM 32 L4, L1, L0) ve nRF 24 L01 radyo yongalar1 entegre edilerek kullanılmıştır.

Spesifik ACS712ELC sınıfı komponentler, geliştirilecek panolara entegre edilerek ARM tabanlı mikro işlemci mimarisine uyumlu sayaç fonksiyonlu algılayıcılar geliştirilmiştir. ARM işlemci tabanlı ve IEEE802.15.4 node içeren kablosuz algılayıcı ağı sinyal yönlendirici ünitesi kullanılarak kablosuz veri alışverişi kapasitesi ve hızının artırılması sağlanmıştır. Bu yeni donanım platformu EOS kablosuz iletişim protokolüne adapte edilmiştir.

Projenin yazılım geliştirme süreçlerinde kullanılan başlıca teknolojiler şunlardır;

-PYTHON: «ARM tabanlı» kompakt bilgisayarın «master» olarak çalışıp tüm «slave» olan «STM 32» işlemci bulunan kablosuz algılayıcı ve kontrol ünitelerine gönderilen verilerin toplanması ve toplanan verilerin anlamlandırılıp veritabanına kaydedilmesi işlemi için kullanılmıştır. kullanılmıştır.

-HTML-CSS: Bağlama duyarlı Grafiksel Kullanıcı Arayüzlerinin geliştirilmesi için

-Javascript-Jquery-AJAX: Kullanıcı ara-yüzlerinin gerçek zamanlı değişen bölümlerinin anlık olarak yenilenmesi, tarih (zaman aralığı) seçme komponent işlemleri, verilerin güncel olarak son kullanıcıya gösterilmesi işlemleri için kullanılmıştır.

Şekil 3. EOS Enerji Optimizasyon Sistemi.

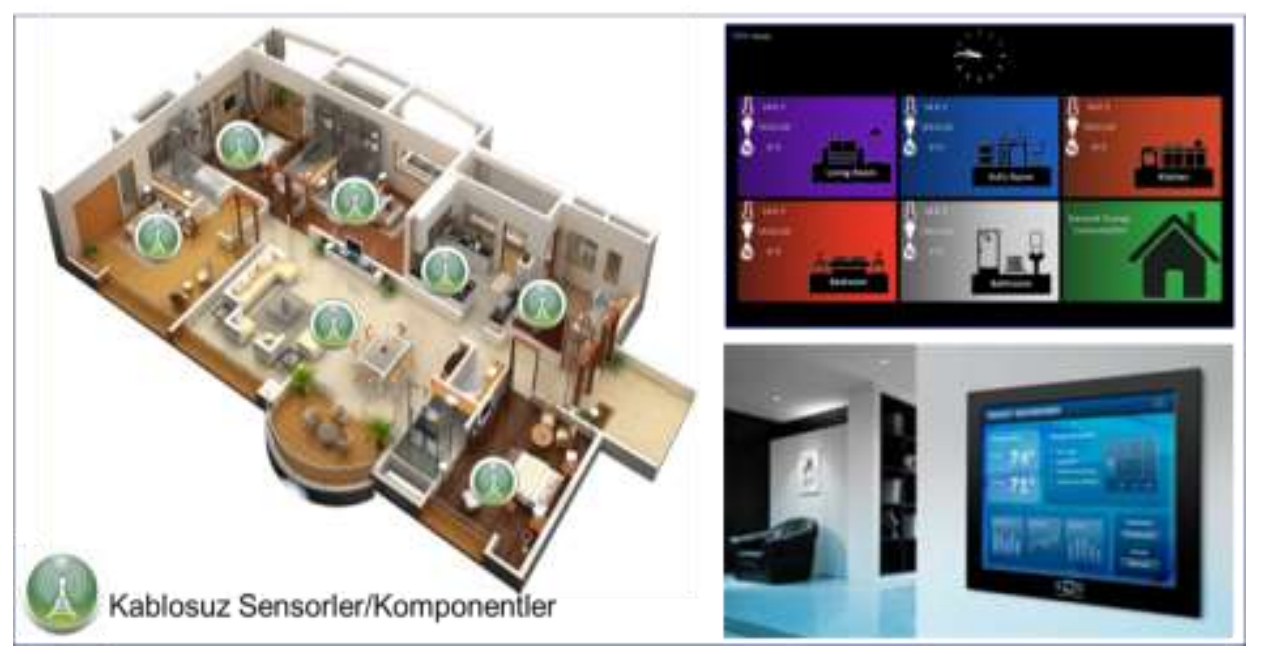

www.turkishstudies.net/appliedsciences 
TÜBİTAK projesi araştırma ve geliştirme süreci sonucu ortaya çıkartılan EOS Sistem Bileşenleri aşağıda verilmiştir.

Şekil 4. EOS-Enerji Optimizasyon Sistemi Bileşenleri Listesi.

\begin{tabular}{|c|c|c|}
\hline No & Donanım ve Yazılım & Tanım \\
\hline 1 & EOS Algılayıcı & $\begin{array}{l}\text { Isı, Işık, Nem seviyelerinin gerçek zamanlı olarak ölçülmesi ve } \\
\text { hareket algılaması için kullanılır. }\end{array}$ \\
\hline 2 & $\begin{array}{l}\text { EOS Soğutma Sistemi } \\
\text { Kontrolörü }\end{array}$ & $\begin{array}{l}\text { Binada bulunan klima sistemlerinin markadan bağımsız olarak } \\
\text { gerçek zamanlı kontrolünü sağlar, optimize eder. }\end{array}$ \\
\hline 3 & $\begin{array}{l}\text { EOS Isıtma Sistemi } \\
\text { Kontrolörü }\end{array}$ & $\begin{array}{l}\text { Sivı tipli 1sıtma sistemlerinde isı seviyesinin gerçek zamanlı } \\
\text { olarak kontrol edilerek optimize edilmesi için kullanılır. }\end{array}$ \\
\hline 4 & EOS İnsan Algılayıcı & $\begin{array}{l}\text { İstenilen alandaki İnsan sayısının gerçek zamanlı olarak tespit } \\
\text { edilmesi için kullanılır. }\end{array}$ \\
\hline 5 & EOS Floresan Dimer & $\begin{array}{l}\text { Floresan teknolojili ış1klandırma sistemlerinin seviyesinin gerçek } \\
\text { zamanlı olarak kontrol ve optimize edilmesi için kullanılır. }\end{array}$ \\
\hline 6 & EOS Dimer & $\begin{array}{l}\text { LED, CFL(Kompakt Florasan Lamba) ve akkor teknolojili } \\
\text { 1şıklandırma sistemlerinin gerçek zamanlı olarak kontrol ve } \\
\text { optimize edilmesi için kullanılır. }\end{array}$ \\
\hline 7 & EOS Aç-Kapa Kontrolörü & $\begin{array}{l}\text { Binada bulunan tüm elektrikli aletlerin aç-kapa fonksiyonlarını } \\
\text { optimize eder. }\end{array}$ \\
\hline 8 & EOS Sayaç & Elektrik sarfiyatının gerçek zamanlı ölçülmesi için kullanılır. \\
\hline 9 & EOS Kelepçeli Sayaç & $\begin{array}{l}\text { İstenilen alanın ve cihazın elektrik sarfiyatının gerçek zamanlı } \\
\text { ölçülmesi için kullanılır. }\end{array}$ \\
\hline 10 & $\begin{array}{l}\text { EOS Sinyal A Ăı } \\
\text { Yönlendiricisi }\end{array}$ & Bütün komponentlerin birbiri ile kablosuz haberleşmesini sağlar. \\
\hline 11 & EOS Tablet Bilgisayar & $\begin{array}{l}\text { Kullanıcı Arayüzü gösterimi ve ilgili yazılımın koşturulması için } \\
\text { kullanılır. }\end{array}$ \\
\hline 12 & $\begin{array}{l}\text { EOS Enerji Optimizasyon } \\
\text { Yazılımı }\end{array}$ & $\begin{array}{l}\text { Yapay Zeka tabanlı kontrol ve optimizasyon algoritmalarından } \\
\text { oluşan yazılımdır. }\end{array}$ \\
\hline
\end{tabular}

\section{Sistem Testleri}

Boğaziçi Üniversitesi Kuzey Yerleşkesi Teknoloji Merkezi (TEKMER) içinde yer alan EOS Sürdürülebilir Enerji Çözümleri A.Ş. firmasına ofis ve laboratuvar alanlarında konuşlandırılan "EOS Enerji Optimizasyon Sistemi” 2014-2018 yılları arasında test edilmiştir. Aşağıda farklı yıllara ve mevsim koşullarına ait üç test sonucu verilmiştir.

• 27.06.2015 Ortalama Ölçülen Enerji Tasarrufu: \% 41,27

• 10.07.2016 Ortalama Ölçülen Enerji Tasarrufu: \% 40,03

• 14.02.2017 Ortalama Ölçülen Enerji Tasarrufu: \% 30,23

Test Edilen Parametreler:

- EOS Soğutma Sistemi Kontrolörü tarafindan kontrol edilen Bina Isıtma / Soğutma Sistemleri:

○ 1 adet klima (Airfel AP09-3102 / R2 Soğutma: 9000 BTU / h Isitma: 9000 BTU / h) soğutma ve 1sitma işlevselliğine sahip. 
- EOS Dimer tarafından kontrol edilen Bina Aydınlatma Sistemleri:

- Enerji tasarruflu ampullere sahip 8 bağımsız lamba (Philips Tornado 20W Dimmable).

- EOS Floresan Dimer tarafindan kontrol edilen Bina Aydınlatma Sistemleri (floresan)

- 1 floresan tipi aydınlatma sistemi (Philips TL-D 36W).

- EOS Aç-Kapa Kontrolörü tarafindan kontrol edilen elektriğe bağlı ofis aletleri:

- Panasonic LED Flat 42 İnç Akıllı TV.

- HP Office Jet 7500 A Yazıc1.

○ Elektrikli Su Isiticisı.

\section{Test Prosedürleri}

i. Isıtma / Soğutma Sistemleri, Aydınlatma Sistemleri ve Ofis Cihazları EOS Enerji Optimizasyon Sistemine bağlıdır.

ii. Isıtma / Soğutma Sistemleri, Aydınlatma Sistemleri ve Ofis Cihazları ayrı bir elektrik ölçere bağlıdır.

iii. Ölçülen "Dış Sıcaklık, İç Nem Seviyesi ve İç Sıcaklık” tabloya kaydedilmiştir.

iv. EOS Enerji Optimizasyon Sistemi çalışmıyorken bağlı bina sistemlerinin toplam gerçek elektrik tüketimi ölçülür (Test Adı: Varsayılan Test). Ölçülen elektrik tüketimi tabloya kaydedilir (Şekil 5'de verilen $\mathrm{kW} / \mathrm{s}$ değerleri).

v. EOS Enerji Optimizasyon Sistemi çalışırken bina sistemlerinin toplam gerçek elektrik tüketimi ölçülür (Test Adı: Test 1). Ölçülen elektrik tüketimi tabloya kaydedilir (Şekil 5 'de verilen $\mathrm{kW} / \mathrm{s}$ değerleri).

vi. Test değerleri, en son "Varsayılan Test" değerleri ile karşılaştırılır.

vii. Saat başı ölçülen enerji tasarrufu hesaplanmış ve tabloya kaydedilmiştir (Şekil 5 'de verilen Enerji Tasarrufu sütunu).

viii. Günlük ortalama enerji tasarrufu hesaplanmış ve tabloya kaydedilmiştir. (Şekil 5'de verilen Günlük Enerji Tasarrufu Ortalaması).

Şekil 5. EOS Enerji Optimizasyon Sistemi Test Sonuçları.

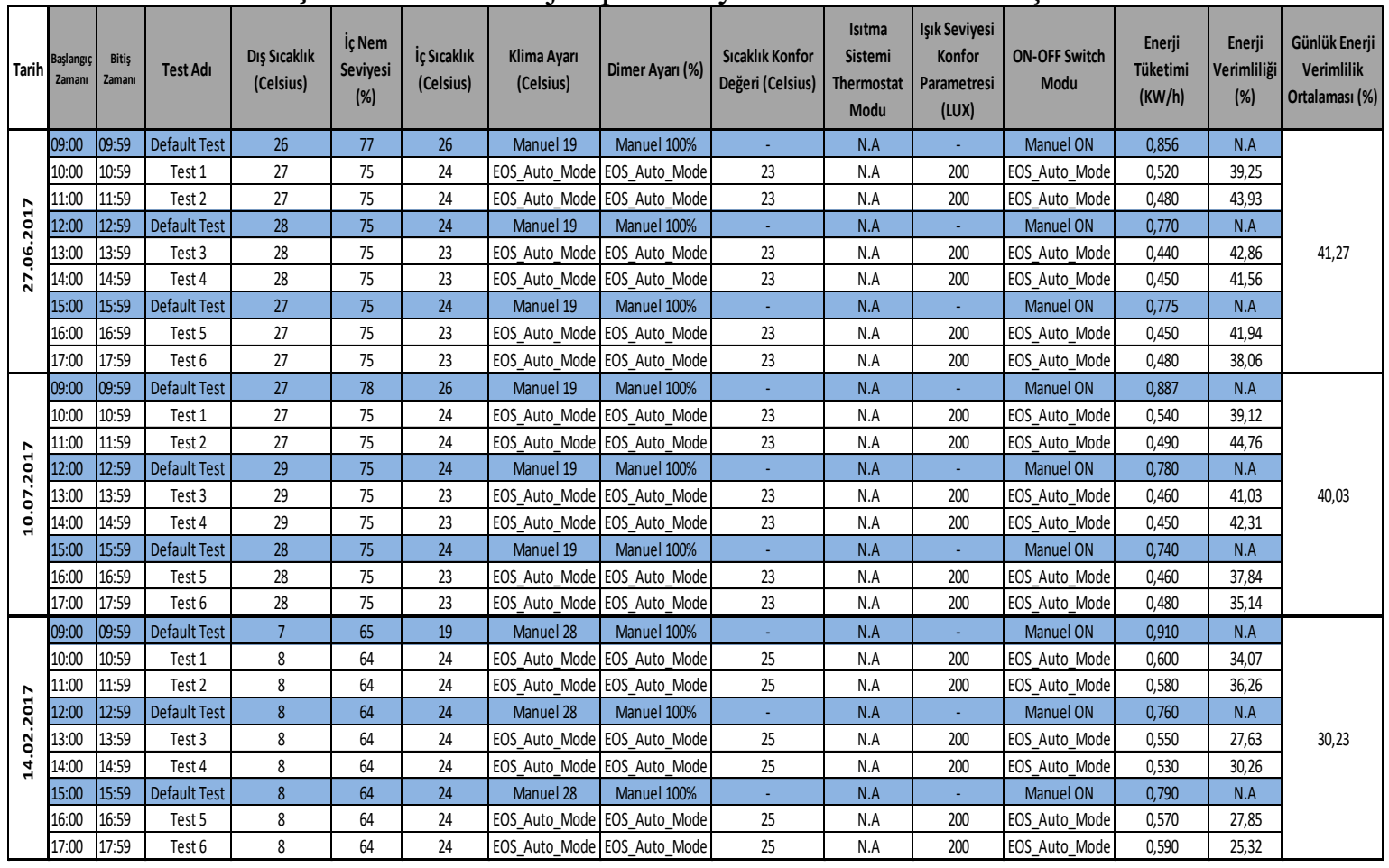




\section{Test Sonuçları}

TÜBİTAK destekli AR-GE projesi kapsamında geliştirilen EOS-Enerji Optimizasyon Sistemi, Boğaziçi Üniversitesi Kuzey Yerleşkesi Teknoloji Merkezi (TEKMER) içinde yer alan ofis ve laboratuvar alanlarında uygulanarak kış mevsimi ve yaz mevsimi koşulları altında test edilmiştir.

Sistem kış mevsimi performansının ölçülmesi amacı ile 14 Şubat 2017 tarihinde saat 09:00 ve 18:00 arasında saatlik karşılaş̧ırmalı teste tutulmuştur. Test sürecinde bina enerji kullanımı geliştirilen sistem manuel durumda iken yani sistemin otomatik olarak binayı yönetmediği zaman aralığında ölçülmüştür. Bu ölçülen tüketim değeri, sistemin otomatik durumda iken yani sistemin binayı otomatik olarak yönettiği zaman aralığında ölçülen tüketim değeri ile karşılaştırılmıştır.

Test sonucunda sistemin 14 Şubat 2017 tarihinde ortalama \%30,23 oranında enerji verimliliği sağladığı ölçülmüştür.

Sistem yaz mevsimi performansının ölçülmesi amacı ile Haziran ve Temmuz 2017 aylarında test edilmiştir.

27 Haziran 2017 tarihinde yapılan testte geliştirilen sistemin ortalama \%41,27 oranında enerji verimliliği sağladığı gözlenmiştir.

10 Temmuz 2017 tarihinde yapılan testte sistemin sağlandığ 1 enerji verimlilik oranın ortalama \%40,03 olduğu kayıt edilmiştir.

Grafik 1: EOS Test Sonuç Grafiği.

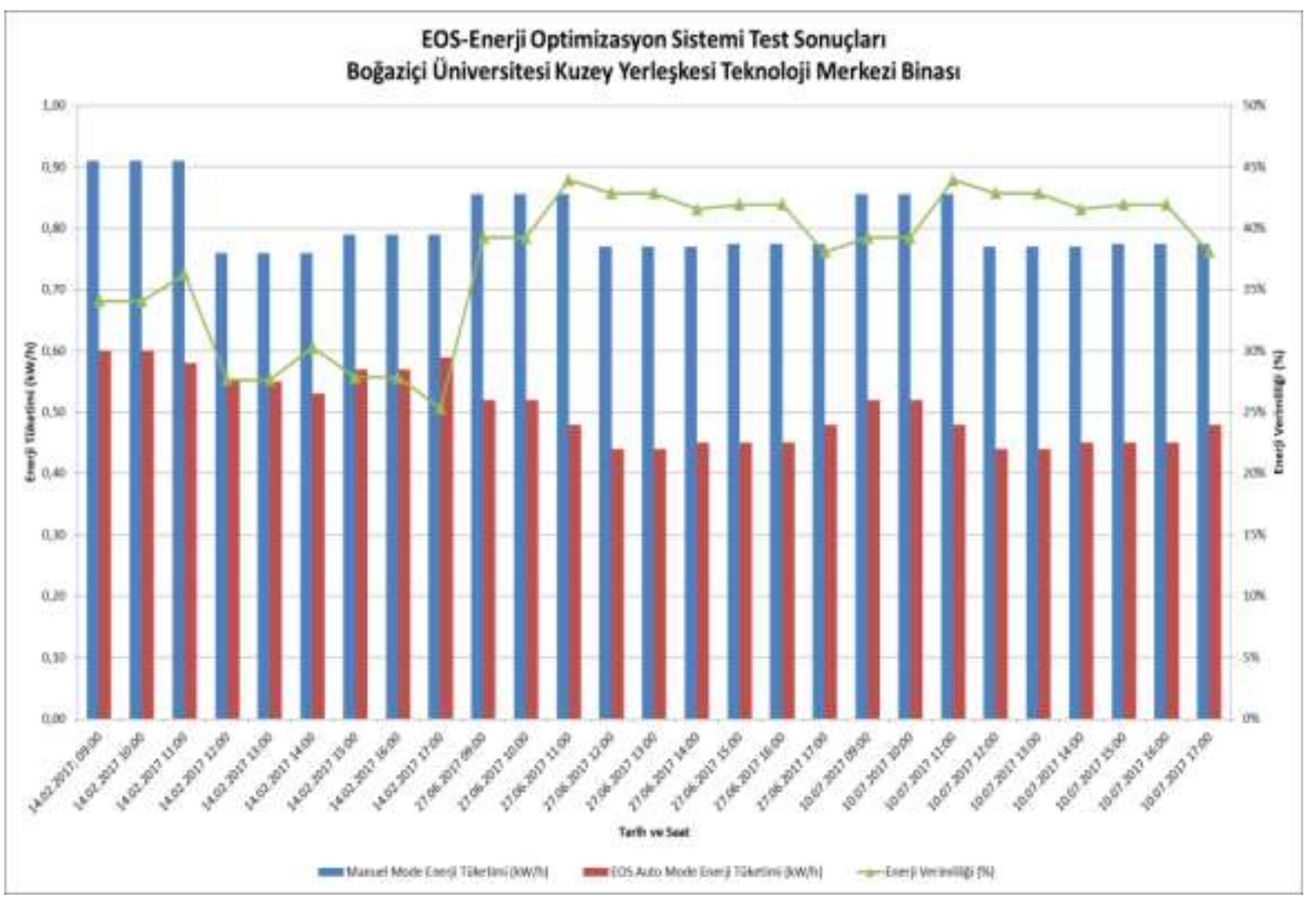

Grafik 1, geliştirilen sistemin test edildiği sürelerde sistem kapalıyken ve çalışırken kayıt edilen bina enerji tüketim değerlerini ve enerji verimlilik oranlarını göstermektedir. Grafikten de anlaşılacağı üzere geliştirilen sistemin yaz aylarında sağladığı enerji verimlilik oranı kış aylarına 
göre daha fazladır. Buna yaz aylarında artan dış sıcaklık nedeni ile iç ortamın klima kullanımı ile soğutulması neden olmaktır. Klima sistemlerinde soğutma sırasında devreye giren kompresörün enerji tüketimi klimanın 1sıtma moduna göre daha fazladır. Yaz mevsiminde klima sistemlerinin geliştirilen sistem ile etkin kontrolü sağlanarak oransal olarak kış mevsimine göre daha yüksek enerji verimliliği sağlanmasına neden olmaktadır.

\section{Tartıșma}

$\mathrm{Bu}$ çalışmada "Binalarda Enerji Verimliliği için Gerekli Algılayıcıların Özgün Olarak Geliştirilmesi Projesi" kapsamında binaların enerji verimliliğinin sağlanması amacı ile geliştirilmiş enerji optimizasyon sistemi ar-ge süreçleri ile birlikte ele alınmış, EOS A.Ş. kuruluşuna ait ofis ve laboratuvar alanlarında test edilmiş ve elde edilen verimlilik değerleri ortaya konmuştur.

Test edilen sistemde aydınlatma, ısıtma ve soğutma parametreleri ele alınmıştır. Test yeri olan İstanbul ili, yazları sıcak ve kurak, kışları 1lık ve yağışı olan Akdeniz ikliminden yazları sıcak ve kışları 1lık ama her mevsim yağış̧ı Karadeniz iklimine geçişin gerçekleştiği bir bölgede yer alır (İiDEP, 2020). İstanbul'un coğrafik konumu, yapılan testlerin sistemin farklı iklim koşullarında test edilebilmesi avantajını da beraberinde getirmiştir.

Türkiye'de ev sahipleri tarafından ödenen enerji fiyatları sürdürülebilir enerjiye geçişi finanse etmek için ücretlendirilen ağ ücretleri ve piyasada oluşan fiyatlar temelindedir.

Sistem testleri, EOS Enerji Optimizasyon Sisteminin farklı iklim koşullarında dahi hedeflenen $\% 25$ 'lik enerji verimlilik değerlerinin üstünde bir performans ortaya koyduğunu göstermiştir. $\mathrm{Bu}$ noktada bulgularımıza göre elde edilecek faydalar ödenen enerji fiyatları temelinde yatırım geri dönüş süresinin görece kısa bir dönemde karşılanabileceğini ortaya koymaktadır.

$\mathrm{Bu}$ sistemin farklı bina tiplerinde uygulanması ile bina sahiplerinin yararlanabileceği ekonomik faydanın yanı sıra, elde edilebilecek enerji verimlilik değerleri ile karbon emisyonlarının da önemli ölçüde düşürülebileceği görülmüştür. İncelenen tüm kategorilerdeki faydalar birbiriyle ilişkilidir, bu da enerji verimliliği sonucu elde edilebilecek farklı ve çoklu faydaların bütün spektrumu kapsayacak şekilde analiz edilmesini gerektirir.

Türkiye ve Avrupa Ülkeleri, vatandaşlarına enerji verimliliğinin önemine yönelik farklı tanıtım kampanyaları sunmalarına rağmen, tüm avantajları gösteren ve son kullanıcıları yönlendiren bütüncül bir yaklaşımı ortaya koyamamaktadırlar. Bu şekilde eksik kurgulanmış yaklaşımlar, EOS-Enerji Optimizasyon Sistemi ve buna benzer sistemlerin ülkeler bazında yaygınlaşmasını da engelleyerek, Kyoto, Kopenhag ve en son olarak Paris iklim zirvesinde kararlaştırılmış olan enerji verimlilik ve karbon emisyon hedeflerine de ulaşmayı imkânsız hale getirmektedir. $\mathrm{Bu}$ noktada mevcutta hızlanarak artan çevresel problemlere yönelik, karar mercilerinin tanıtım ve yönlendirmeleri haricinde, enerji verimlilik sistemlerinin kesin kurallarla ve kanunlarla uygulanabilir olması önemlidir. Daha fazla bina ve konut sahibi, daha iyi enerji yönetimi ile gerçekleşecek farklı ve çoklu faydaları ne kadar çok tanıyabilir ve yatırımlarını bu doğrultuda gerçekleştirebilirse, ülkelerin uzun vadeli enerji politikası hedeflerine ulaşmaları o ölçüde kolay olacaktır.

Bunların 1şığında, ar-ge projesinin ve geliştirilen sistemin son kullanıcıya, ülkeye ve çevreye sağlayacağ çoklu fayların irdelenerek proje sonuçlarının farklı açılardan değerlendirilmesi amacı ile yapılacak bir tekno-ekonomik analiz çalışması faydalı ve tamamlayıcı olacaktır.

\section{Sonuç}

Bu makalede, TÜBİTAK Teydeb 1501 Sanayi AR-GE Projeleri Destekleme Programı çerçevesinde 2014-2017 yılları arasında yürütülmüş 3140107 proje numaralı "Binalarda Enerji 
Verimliliği için Gerekli Algılayıcıların Özgün Olarak Geliştirilmesi Projesi" kapsamında binaların enerji verimliliğinin sağlanması amacı için gerekli olan kablosuz ağlı gömülü teknolojileri içeren 12 farklı tipte özgün olarak geliştirilmiş algılayıc1, kontrol ünitesi, donanımlara ait gömülü yazılımlar, kablosuz haberleşme protokolü, çok boyutlu veri ambarı, yapay zeka tabanlı akıllı kontrol algoritmalarından oluşan ve enerji optimizasyon yazılımı ve grafiksel kullanıcı ara yüzlerinden meydana gelen entegre enerji optimizasyon sistemi geliştirilme süreçleri ile açıklanmıştır.

Geliştirilen sistem Boğaziçi Üniversitesi Kuzey Yerleşkesi Teknoloji Merkezi (TEKMER) içinde yer alan EOS Sürdürülebilir Enerji Çözümleri A.Ş. firmasına ait ofis ve laboratuvar alanlarında konuşlandırılarak test edilmiş ve enerji verimlilik seviyeleri ölçülmüştür.

Yapılan testler sonucunda geliştirilen sistemin farklı mevsimsel koşullar altında en düşük $\% 30,23$ ile en yüksek \%41,27 arasında enerji verimliliği sağladığı kayıt altına alınmıştır.

$\mathrm{Bu}$ çalışmada irdelenen ar-ge projesi ve projenin sonucu olan enerji optimizasyon sisteminin ekonomik, çevresel ve sosyal göstergeler açısından sağladığı çoklu faydaların değerlendirileceği bir tekno-ekonomik analiz çalışmasının ileri araştırma safhasında yapılması çalışma için faydalı ve tamamlayıcı olacaktır.

\section{Teşekkür Bölümü}

$\mathrm{Bu}$ makalede irdelenen çalışma, Türkiye Bilimsel ve Teknolojik Araştırma Kurumu (TÜBİTAK) Teknoloji ve Yenilik Destek Programları Başkanlığı (Teydeb) 1501 Sanayi AR-GE Projeleri Destekleme Programı kapsamında, EOS İstanbul Sürdürülebilir Enerji Çözümleri A.Ş. firması tarafindan yürütülmüş 3140107 proje numaralı "Binalarda Enerji Verimliliği için Gerekli Algılayıcıların Özgün Olarak Geliştirilmesi Projesi" çıktılarıdır.

Bu projede Proje Yöneticisi ve AR-GE Yöneticisi olarak görev alan makalenin yazarları, başta TÜBITTAK olmak üzere projede görev alan ve desteklerini esirgemeyen tüm paydaşlara teşekkürlerini sunar.

\section{Kaynakça}

Becker M., Knoll P. (2011). Untersuchungen zu Energieeinsparpotenzialen durch Nutzung integrierter offener Gebäudeautomationssysteme auf Basis der Analyse DIN V 18599 und prEN 15232, Hochschule Biberach, 2007, Studie im Auftrag der LonMark Deutschland e.V., Aachen.

Bogdan A., Chantal D., Marina E., Joana M., Ingeborg N., Oliver R. (2011). Europe's buildings under the microscope, A country-by-country review of the energy performance of buildings. Buildings Performance Institute Europe (BPIE), 2011.

BOTAS (2017). BOTAS Sektör Raporu. https://www.botas.gov.tr/uploads/galeri/5c6ded9d4cd5f20.02.2019sektorap_2016.p df

BOTAS (2019). BOTAS Sektör Raporu. https://www.botas.gov.tr/uploads/galeri/844491-2018sektorraporu.pdf

Cohen, R. \& Bordass, W. \& Field, J. (2004). Energy performance of non domestic buildings: closing the credibility gap. In Building Performance Congress.

DIN-Deutsches Institut für Normung e.V. (2007). DIN EN 15232: Energieeffizienz von Gebäuden Einfluss von Gebäudeautomation und Gebäudemanagement, Deutsche Fassung EN 15232:2007. Berlin, Germany. https://www.zvei.org/fileadmin/user_upload/Verband/Fachverbaende/Elektroinstallationssy 
steme/Studie_Energieeffizienz_durch_Gebaeudeautomation/Kurzfassung-ZVEI-StudieEnergieeffizienz-durch-Gebaeudeautomation.pdf

EC (2011). A Roadmap for moving to a competitive low carbon economy in 2050, SEC (2011) 289 final.

https://ec.europa.eu/clima/sites/clima/files/strategies/2050/docs/roadmap_fact_sheet_en.pdf

EC (2011). European Comission - Energy. www.ec.europa.eu/energy/efficiency/buildings/buildings_en.htm

EUROSTAT a (2020). Energy Production and Imports-a statistical overview. https://ec.europa.eu/eurostat/statisticsexplained/index.php/Energy_production_and_imports

EUROSTAT b (2020). Oil and Petroleum Products-a statistical overview. https://ec.europa.eu/eurostat/statisticsexplained/index.php?title=Oil_and_petroleum_produ cts_-_a_statistical_overview\#Oil_imports_dependency

Gökçe, C. ve Erol, M. (2020) Türkiye'de Tasarruf Açı̆̆ı ve Enerji Açı̆̆ının Ekonomik Büyüme ile İlişkisi: Nedensellik Analizi. Dumlupinar Üniversitesi Sosyal Bilimler Dergisi. 64, 102122;2020. E-ISSN: 2587 005X http://dergipark.gov.tr/dpusbe

Gökçe, H. U. (2010). Multi-Dimensional Analysis of Building Performance Data for Energy Efficient Building Operation, PhD Thesis, National University of Ireland, Cork, Ireland.

Gökçe, H. U ve Gökçe K. U. (2011). Multi Dimensional Information Management Platform for Wireless Embedded Monitoring of Building Performance Data. Proceedings of the $11^{\text {th }}$ International Conference on Construction Applications of Virtual Reality, Weimar, Germany. ISBN: 978-3-86068-458-0.

Gökçe H. U., Gökçe K. U. (2013) Integrated system platform for energy efficient building operations. Journal of Computing in Civil Engineering. 10.1061/(ASCE)CP.19435487.0000288 (5 Jan 2013) SCI A.

Gökçe, H. U ve Gökçe K. U. (2013). Holistic System Architecture for Energy Efficient Building Operation. Journal of Sustainable Cities and Society. pp. 77-84 DOI information: 10.1016/j.scs.2012.07.003.

Itard, L., Meijer, F., Vrins, E., \& Hoiting, H. (2008). Building renovation and modernisation in Europe: State of the art review. ERABUILD. Nederlands: TU Delft, 2008. http://iibw.at/documents/2008\%200TB\%20TU\%20Delft.\%20Erabuild\%20Building.\%20R enovation\%20Europe.pdf

İIDEP (2020). 2016 - 2020 İstanbul İklim Değişikliği Eylem Planı.

Erişim Adresi: https://www.iklim.istanbul/iklim/

Jagemar, L., Olsson, D., Schmidt, F. (2007). The EPBD and Continuous Commissioning. Project Report. Building EQ. EIE/06/038/SI2 .448300, EU.

https://ec.europa.eu/energy/intelligent/projects/sites/ieeprojects/files/projects/documents/bu ilding_eq_the_epbd_and_continuous_commissioning_en.pdf

Keller, M., O'Donnell, J., Keane, M., Gökçe, H. U. (2008). Integrating the specification, acquisition and processing of building performance information. Journal of Tsinghua Science and Technology, vol. 13, no. 1, pp. 1-6. ISSN 1007-0214 01/17. http://citeseerx.ist.psu.edu/viewdoc/download?doi=10.1.1.457.374\&rep=rep1\&type=pdf

Kimball (2004). The data warehouse ETL toolkit: practical techniques for extracting, cleaning, conforming, and delivering data. Caserta, Joe, 1965-. Indianapolis, IN. Wiley. ISBN 9780764579233 . OCLC 57301227. 
OME (Observatoire Méditerranéen de l'Energie). (2014). Mediterranean Energy Perspectives TURKEY.

http://www.tenva.org/wp-content/uploads/2014/09/MEP-Turkey-Executive-SummaryEnglish.pdf

Price, L. (2006). Sectoral Trends in Global Energy Use and Greenhouse Gas Emissions. Lawrence Berkeley National Laboratory. USA. https://www.osti.gov/servlets/purl/888753

UNFCCC (2018). United Nations Climate Change Annual Report 2017. ISBN: 978-92-9219-175-

7. https://unfccc.int/resource/annualreport/media/UN-Climate-AR17.pdf

VDMA-German Engineering Federation (2008). Energy-efficiency of Buildings. Germany. Beuth Verlag GmbH 2007, pp. 79. 